\title{
INHOUSE VERSUS PUBLIC VIDEOTEX SYSTEMS
}

H.A. Maurer

Institut für Informationsverarbeitung, Universität Graz, Austria

I. Sebestyen

International Institute for Applied Systems A nalysis, Laxenburg, Austria

RR-83-30

December 1983

Reprinted from Computer Networks, volume 7 (1983)

INTERNATIONAL INSTITUTE FOR APPLIED SYSTEMS ANALYSIS

Laxenburg, Austria 
Research Reports, which record research conducted at IIASA, are independently reviewed before publication. However, the views and opinions they express are not necessarily those of the Institute or the National Member Organizations that support it.

Reprinted with permission from Computer Networks 7:329-342.

Copyright @ 1983 Elsevier Science Publishers B.V. (North-Holland)

All rights reserved. No part of this publication may be reproduced or transmitted in any form or by any means, electronic or mechanical, including photocopy, recording, or any information storage or retrieval system, without permission in writing from the copyright holder.

Printed by Novographic, Vienna, Austria 


\section{FOREWORD}

The Information Technology Task of IIASA's former Management and Technology Area carried out a couple of videotex related studies in 1981 and 1982. This report was written within the above framework in 1982, at which time videotex development seemed to be moving in two extreme directions, into solely inhouse and solely public videotex systems. In this report the authors try to analyze the relation between the two types of systems and show that these systems are not and should not be independent of each other, and that they should complement each other rather than compete. The time since the writing of this report has proved that the outlined concept was correct; nowadays more and more systems are appearing on the market with the suggested capabilities.

TIBOR VASKO

Leader

Clearinghouse Activities 


\section{Inhouse Versus Public Videotex Systems}

\author{
H.A. Maurer \\ Inst. für Informationsverarbeitung, Technische Universität Graz, \\ Schiesstadtgasse 4a, A-8010 Graz, Austria
}

and

\section{Sebestyen}

International Institute for Applied Systems Analysis, 2361 Laxenburg, Austria

The aim of this paper is to analyse the relation between inhouse and public videotex systems and show that these systems are and should not be independent of each other and that they can and should complement each other rather than compete.

Keywords: Videotex, inhouse videotex systems, public videotex systems, computer networks, distributed processing, transactions, videotex network architecture, videotex gateway, economy aspects of videotex, usage aspects of videotex.

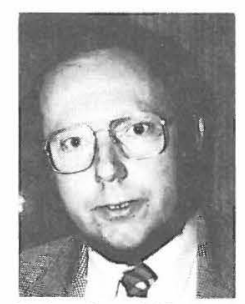

Dr Maurer studied mathematics at the University of Vienna and at the University of Calgary, Canada, and received a Ph.D from the University of Vienna in 1965. He worked as Systems Analyst with the Government of Saskatchewan in 1963, Mathematician-Programmer with the IBM Recearch Lab Vienna, 1963-1966. Assiscont and Associate Professor for Comtant and Associate Professor for Computer Science at the University of Calgary 1966-1971. Full Professor and University of Karlsruhe 1971-1977. Since 1978 he has been Professor and Chairman for Computer Science at the University of Graz and part-time staff member of the International Institute for Applied Systems Analysis (IIASA) since 1981. His main interest areas include languages, data structure and videotex systems.

\section{North-Holland}

Computer Networks 7 (1983) 329-342

\section{Introduction}

Inhouse videotex systems are gaining more and more attention. Although the original concepts of videotex was defined by the British Post Office Research Center and Sam Fedida in 1972 a as public service, during the last few years the use of inhouse videotex has been growing faster than that of public systems. It was believed during the early days of videotex public service in 1979 in the UK that public videotex services, such as the British Post Office's own Prestel would serve both business and private needs at the same time. Although it was believed that both types of usage would take off right at the beginning of the service, it was expected that initially the pace of growth in the business sector would outweigh that of the home sector. This expectation has not only been fulfilled in the UK, but also the present weight of business users suggests that the role of the home user might have been overestimated as a whole. Where are the interests of the business user sector in the present videotex services? There is first of all a need for useful information offered by other business information providers, such as stock exchange information for stock and commodity brokers, weather information for farmers, exchange rate information for foreign trade companies, etc., only to name a few.

There is also a second category of business users' needs, which brought about the creation of so-called Closed User Groups (CUGs) in present

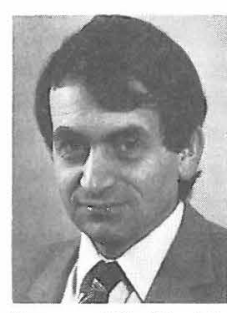

Dr. Sebestyen studied Electrical Engineering at the Technical University in Budapest: he received his M.S. in 1970 and his Ph.D. in 1974, both from the Technical University. He then joined, as computer hardware engineer, the computing laboratory of the institute for Coordination of Computer Techniques. His special field of interest during this period was software engineering; from 1974 to 1977 ware engineering; from 1974 to 1977
he participated in a number of joint research projects on this subject with Siemens AG, Munich. From 1977 to 1978 he worked as an expert on Management Information Systems at the UNIDO Headquarters in Vienna, and joined IIASA in 1978. While at IIASA he has been involved with the activities of the informatics Task, and Management and Technology Area. Here he is carrying out impact studies on new information technologies such as videotex, teletext and videodiscs. 
videotex services. Members of CUGs have the right to access a set of information frames that other users of the system have not. In this manner business users can get information not only from publicly available frames such as weather or exchange rates, but also information that is the proprietary right of the CUG they belong to. The concept of the CUG, however, brought a new idea along. Organizations and business groups that could not afford to buy and operate their own information systems, or where the rudimentary methods offered by videotex are perfectly adequate, were to create CUGs for themselves. Very often they were not really interested in the information offered by other information providers, they basically wanted to rent "raw" videotex resources and services from the videotex service operators. From this scenario a "jump" to inhouse videotex systems is not surprising. When economy of scale is demanding, it is cheaper in the long run to build up one's own inhouse videotex system than to rent it run from the PTT.
However, the distinction between inhouse often also called private - and public systems is not so clear. The aim of this paper is to analyze the relation between inhouse and public videotex systems and show that these systems are not independent of each other and that they can and should complement each other rather than complete.

\section{Aspects and Uses of Videotex Networks}

In order to understand the relation between inhouse and public videotex systems, we have to give first a short overview of some typical videotex networking philosophy.

\subsection{Star-shaped Videotex Networks}

The simplest form of a videotex network is actually the Star-shaped Videotex Network (Figure 1). In this manner the videotex service center is

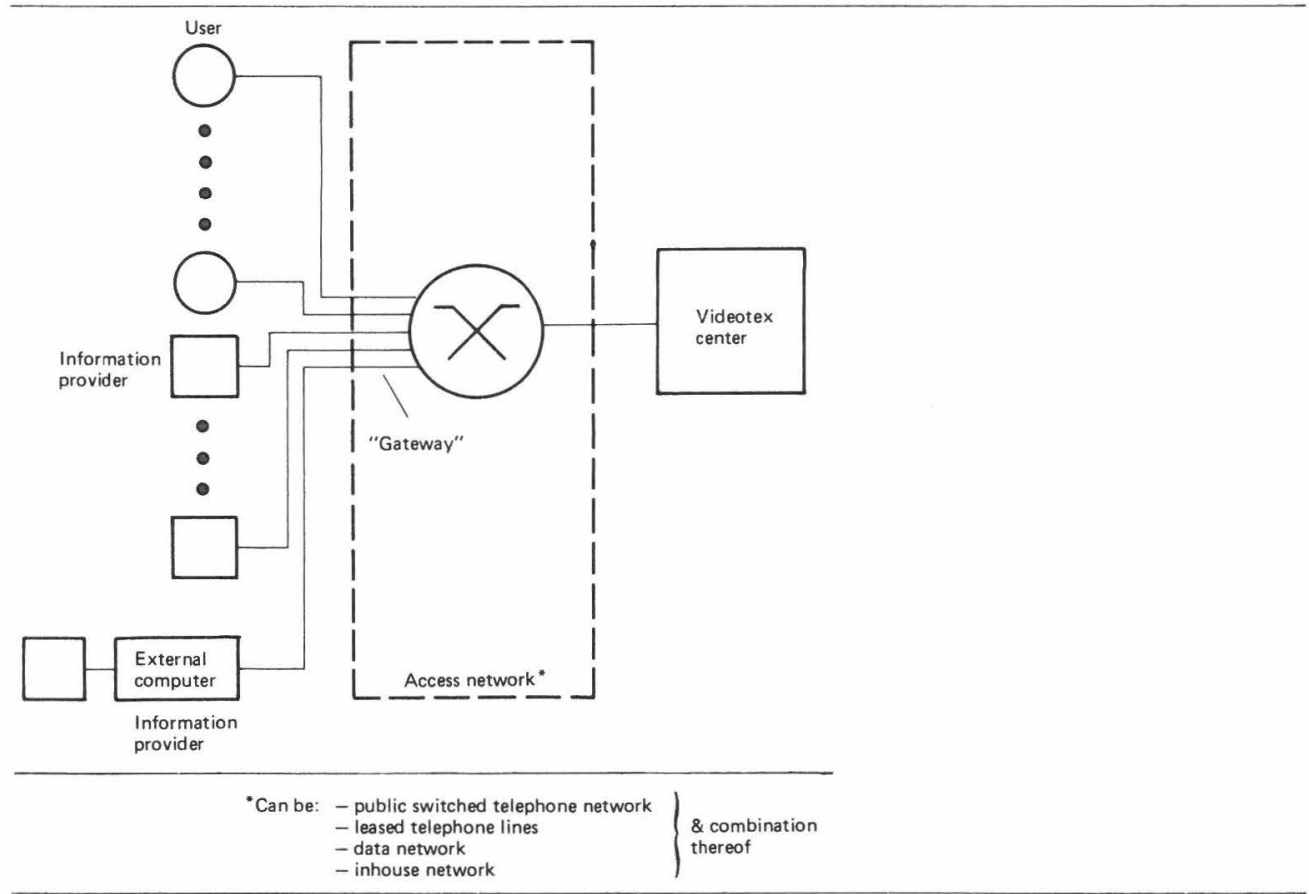

Fig. 1. Star-Shaped (Public or Inhouse) Videotex Network. 
nothing more than a time-sharing computer-center dedicated to videotex applications, such as rudimentary information retrieval and transaction handling. Access to the network both by users and information providers is provided usually through public switched telephone networks, and in some cases through leased lines or data networks. Usually, when the videotex service is small - as is the case in most countries presently conducting videotex experiments or field trials - the starshaped network approach is adopted. In Austria, for example, at present there is only one videotex service computer, which is located in Vienna; all access by users and information providers is made through conventional telephone lines. In order to make connections affordable and economically justifiable from all parts of Austria the Austrian PTT adopted the policy of charging only local charges for any connection made to the videotex center regardless of the distance of the videotex user or information provider from the center. It is rather clear that this decision is more politically than economically based, and is only a temporary one, anticipating that in 1984 a nationwide videotex network and service will become available, where the present star-shaped videotex network will be superseded by a real videotex network comprising regional videotex centers that will collect and handle all local and regional communication between the videotex network and its users.

From the very beginning it was rather clear for the PTTs that starshaped videotex networks are only the start for such a service. As long as 200-300 users are connected to the system, where the frequency of access by users is relatively nicely distributed and amounts to a few hours per month,

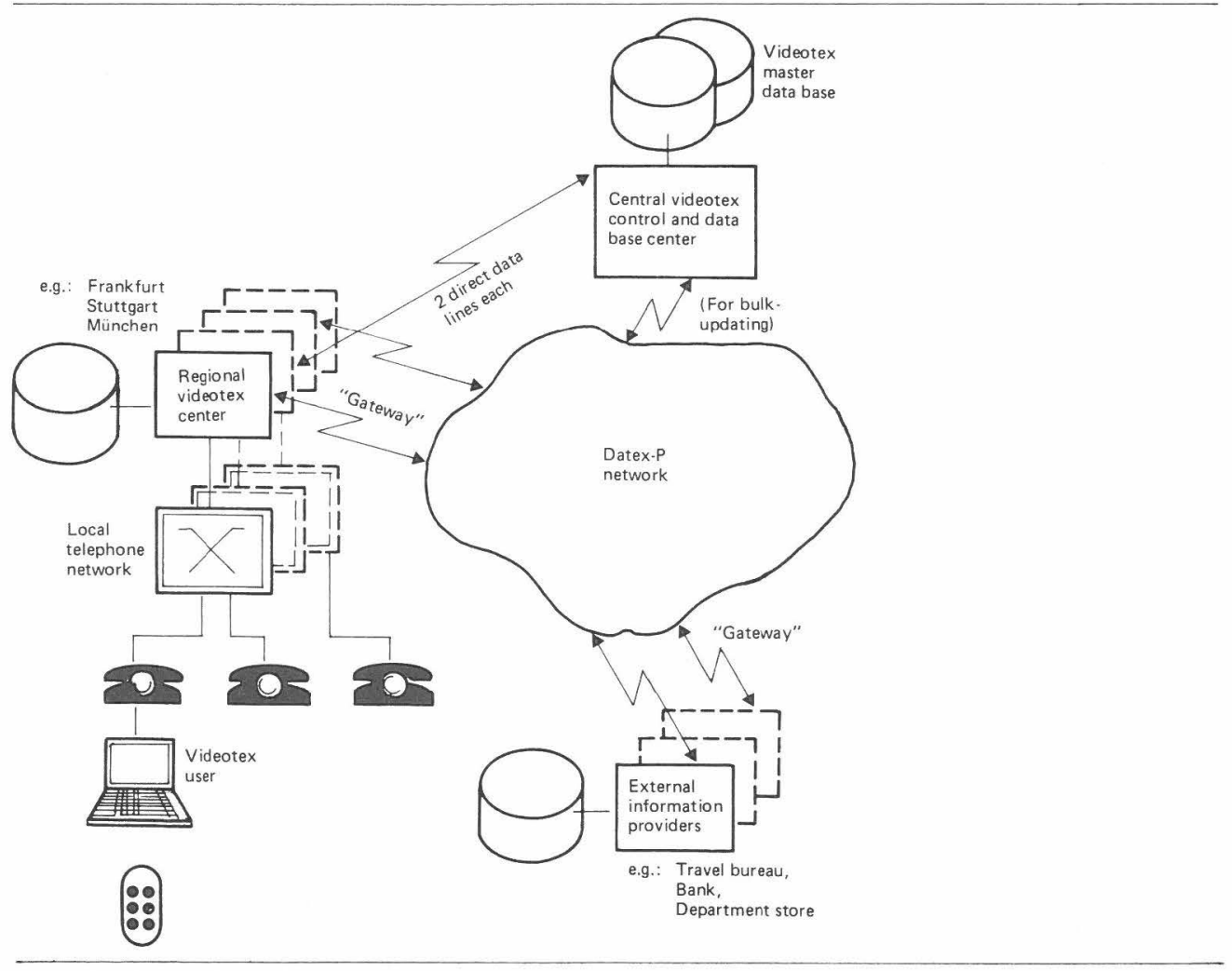

Fig. 2. IBM Concept for the National Videotex Network in the FRG. 
not too many disturbances in the service are expected. After some service experience in several field trials one can say that the PTTs were right in their assumption: slow response time in providing service occurs relatively seldom. Nonetheless, most experts agreed that if for some reason all or many users made an attempt to access the system simultaneously, it would probably collapse. In a countrywide system where this is certainly unacceptable it can be avoided by means of parallel processing and even distribution of service loads. It was also quite clear, that in order to achieve countrywide coverage of the videotex service, nationwide videotex networks have to be built and operated. In most countries these networks are or will be implemented in close relation with the national data networks. In more technical terms: in videotex networking - if we take the important concept of "Open Systems Interconnection" (OSI), which has been developed by ISO - the lower level protocol functions (physical, link, and network layers) will be taken over and performed by the national data networks, such as DATEX-P in Austra or West Germany, and the higher lever protocol functions (transport, session, presentation, and application layers) by the national videotex centers, third party computers, users' and information providers' terminals etc.

These "real" videotex networks with multiple videotex service centers, third party computers, and data communication subnetworks will be described at some length in the next chapter.

The functioning of CUGs on the star-shaped videotex networks mentioned earlier is very similar to that of simple time-sharing computer systems: under a given user group identification, many individual users using different account numbers and passwords may work and have access to a common set of data files. In this sense - for certain applications - it is evident that the CUG facility of present starlike videotex "networks" can take over the role of sharing a computer for some groups and companies. And in many cases this is exactly what is happening. In principle, it is possible to buy an inhouse videotex system and to rent its services mainly in CUG format to other groups, companies, etc. Basically, we believe no PTT or other government agency can and should have the right to do anything about it. As a further step, the operator of such an inhouse videotex could also create his own pages and make them accessible to all users. This kind of service would also be perfectly in line with what any time sharing computer service company could do and what many already actually do. By analogy with private time sharing services one could well imagine the emergence of private videotex services. Nonetheless, some PTTs in Europe are afraid that through the above approach private videotex service operators could offer exactly the same services as public videotex. We on the other hand believe that monopoly measures should not be taken, especially in a new field such as videotex. With regard to data communication services it should be clearly understood that public videotex represents "value added services" because it provides services up to the highest, i.e., application oriented level. This step in the history of PTT services is a move to a field where PTTs previously did not have monopolies. Because of the emergence of computational and telecommunication services this step is certainly legitimate, but it should not happen at the expense of the computer service industry. We feel it is essential, and this is one of the claims of this paper, that the carrier's public services such as videotex should live in "peaceful coexistence" with other not public - so-called inhouse - computing and information services.

\subsection{Distributed Videotex Networks}

As soon as videotex networks start to grow, both in their geographical coverage and number of users and services, it becomes clear that the starshaped videotex network concept is far from satisfactory and has to be upgraded to a real, distributed videotex network.

As an example of such a distributed videotex network we present the IBM network concept for a public videotex service to be implemented in the Federal Republic of Germany, starting in 1984.

This "hierarchical" IBM concept, built upon regional videotex centers linked to a central videotex control and data center, is shown in Fig. 2 [12].

The IBM concept is based on three geographically distributed hierarchical levels. The central control and data center - the third level - will be installed in Ulm in South Germany. Both users and information providers, however, may only directly communicate (interactively) with their own regional videotex center - first and second level - 


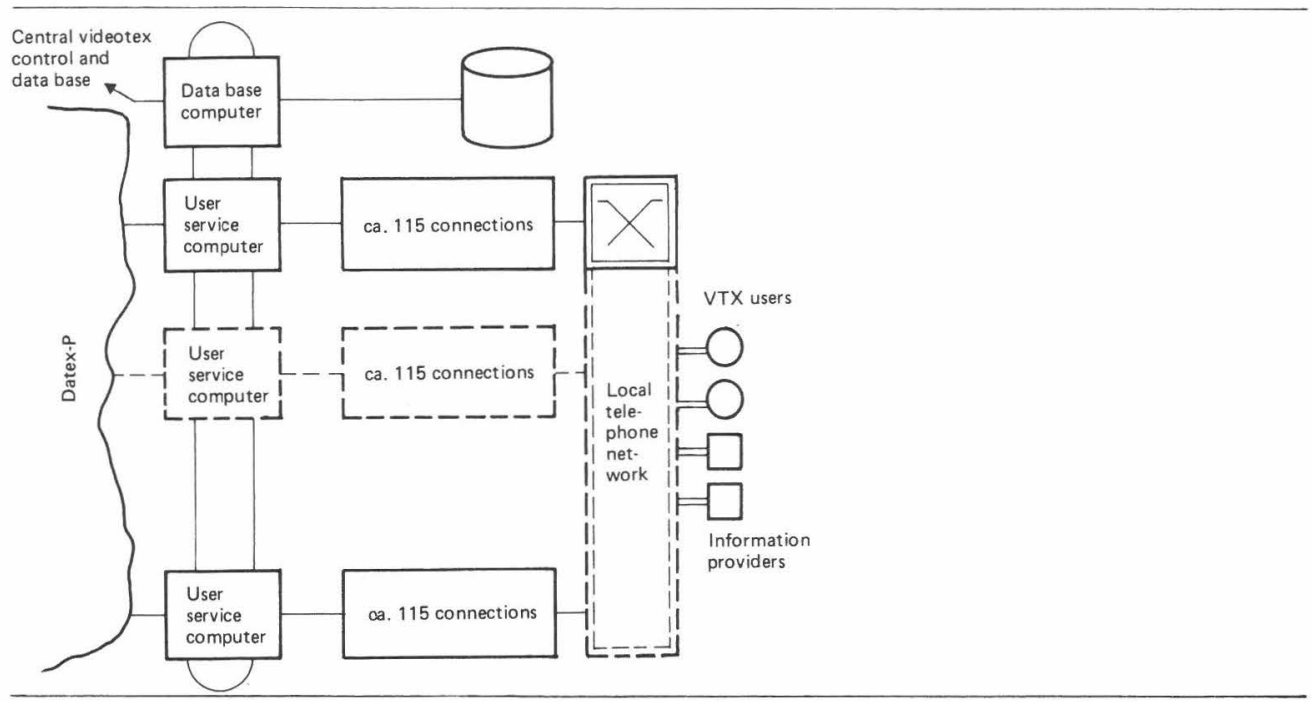

Fig. 3. Structure of a Regional Videotex Center.

via public switched telephone lines or the national DATEX-L (circuit switched) data network. The first level in the hierarchy of computers in the videotex network contains the so-called videotex user service computers attached to the regional videotex centers (Fig. 3).

These IBM series / 1 computers control a group of approximately 115 ports and lines and handle user procedures including logon/logoff, statistics, accounting, etc. The so-called regional database computers (second level) - also IBM series/1 models - are responsible for the management and control of all regional videotex user service computers and the storage of all data needed (also information pages) in a virtual mode for the work of these user service computers. The regional videotex database and the central database work together on the principle of virtual storage, i.e., the information that is accessed most frequently by the users of a given regional center is downloaded into the regional database and stored there temporarily for further access. The master database of the videotex network resides in the central database, and all updates are performed there. In this sense there is not only a hierarchy between the different levels of computers in the videotex network, but also in the databases. As mentioned above, when a videotex user searches for information, segments of the "master database" are copied to the database of the requesting videotex center and stay there until the regional database is filled up with information segment copies; if a user request is then made for a "new" segment of the "master database", the least used segment is overwritten.

When a videotex page has been deleted or updated by an information provider in the "master database", the videotex control center sends a message to all regional videotex centers to delete the page from the regional database, should a copy of it be there. If a new user request for such a page comes along, then the appropriate updated segment will be downloaded into the regional database.

When access to an external computer is requested (through the gateway!), as shown in Fig. 3, the videotex user service computer that is taking care of the requesting user establishes connection to the external computer in question directly through the national PTT packet switching network DATEX-P. The regional database computer does not get involved in these kinds of "conversation" in the sense that pages requested from the external computer would be stored temporarily on 
its own regional database. (Since the "gateway concept" is one of the most important in the videotex concept, we devote the whole next chapter to it.)

The IBM distributed network concept discussed above is typical of many possible others. In other countries, e.g., in the UK, the Prestel network has a different topology and philosophy. For example, the "master database" is fully transferred and stored in all regional databases, whereas the planned Prestel PANDA network already shows certain similarities with the West German concept. More about these and other networks concepts can be found in refs. [11] and [13].

\subsection{The Videotex Gateway}

The philosophy of the videotex gateway to third party computers and especially to third party databases was developed and put into operation first by the German Bundespost in 1981. This new facility basically allows and supports in a transparent way two-way interaction between a videotex terminal and a private business computer system through the national PTT videotex and data networks. The West German Bildschirmtext gateway provides a packet switching interface to the DATEX-P PTT network and through that to the information providers' own computer. The chief advantage of this architecture is that the videotex - DATEX-P network carries all orders, reservations, calculations, etc., entered at any videotex terminal directly into the company's own computer. It is possible, for example, to call up a bank computer from a home videotex terminal, to interrogate the computer to find out the state of an account, perform simple calculations, such as exchange of currency and then to instruct the bank to carry out certain transactions, such as sending the calculated foreign currency to another bank account.

The early use of the gateway brought other advantages with it, such as security: information providers have complete control over who can and should access their information, over the data storage facilities and mode, etc., and all this at their own location. An additional advantage is that locally stored data is considerably more convenient to update.

Another very important advantage and convenience of the gateway is shown in the above example: through the gateway ordinary videotex users are able to access services such as time-sharing type calculations, may access a more sophisticated database manamagement system and database and so on: capabilities and possibilities well beyond standard videotex services. If one takes into consideration - as has been shown in many papers $[2,3,7]$, that in videotex services numerical keypads have only limited value, and for the full spectrum of videotex applications a full alphanumerical keyboard is needed, it becomes rather obvious that with the realization of the gateway concept we have taken a step towards the philosophy of more sophisticated packet switched computer networks and their typical applications.

In this connection a further advantage is that the more sophisticated services offered by the third party computers linked to the gateway do not put too much burden on the videotex network itself and especially on the videotex database computers. This phenomenon goes exactly in the direction of what is called distributed processing. The notion of distributed processing and distributed intelligence in videotex systems moves also in the other direction: towards more local processing and intelligence at the user's side in the form of intelligent videotex decoders, such as MUPID [7,8]. In general, the success of future videotex systems will much depend on the ability to balance the proportion of distributed processing and intelligence on both sides, so that the maximum number of user services is provided at minimum costs and in the most convenient way.

The main significance of the "gateway" to third party computers lies in its capability to allow a direct dialogue between users and the information provider's inhouse computer. If the nature of the dialogue is such that quick response is required by the user, and the number of messages between a user and the computer is high or unpredictable, only then can we talk about a "real" type of interaction between a videotex user and a third party computer. If, however, the number of messages between a user and the computer per user session, per transaction is low, and no instant response is required, for most transactions a type of "conversation protocol" can be defined and introduced, which would perform all interactions by means of a good functioning videotex message service instead of using a real interactive gateway. Let us call this "protocol" type of interaction between videotex user and third party computers. 


\subsection{1. "Real" Interactive Access to Third Party Computers}

A typical example of a "real" type of interactive access is the videotex service of the department store Quelle in the FRG. The Quelle computer - equipped with appropriate hardware and software - is linked through the DATEX-P network and the gateway to the national videotex trials in Düsseldorf and Berlin. Customers of Quelle establish direct dialogues with the Quelle computer through videotex. Users examine the Quelle sales catalog (displayed as information pages), select items of their choice, confirm that the selected items are in stock and then order them. In return the computer sends confirmation of the orders. In banking, similar types of transactions are typical: users may get information about the status of their bank account, they may perform money transactions, and they can carry out simple calculations such as currency exchange or mortgage calculations.

In addition to these applications - as we have pointed out in other studies $[7,10]$ - a number of new applications can be imagined requiring real interactive access to a third party computer. Such an application would be, for example, telecomputing on a third party time sharing computer or teleplaying, telegambling, or educational applications, travel reservation etc. All in all "real" interactive access is needed, where the conversation between user and computer has to be instantaneous and in real time, such as in travel reservations, or in conversations where the nature of the interaction between user and system is not uniform but more complex, such as in telecomputing. In a majority of other cases - as we will explain in what follows - if a well-functioning videotex message service and predefined "interaction protocols" are applied, a "real interactive" gateway between the videotex network to the third party computer is not needed.

\subsection{2. "Protocol-Type" Interactive Access to Third Party Computers}

The above examples of the use of the videotex gateway for accessing the Quelle computer for teleshopping purposes could also be done in a different way.

The Quelle sales catalog in videotex format is loaded on the PTT videotex master database, users make their choice of items, and order them by using the "standard" videotex service. After making his selections, the customer sends an appropriate response frame or message frame over videotex; let us say to the department store Quelle's videotex mailbox. Quelle does not process the incoming transactions instantaneously, real time, but as soon as reasonable and sends a message back to the user's mailbox either with the confirmation that the ordered item is in the mail or to say the item is out of stock, etc. On making his next connection to the system, the user finds the message in his videotex mailbox.

This approach has obviously a minor disadvantage that the response of the department store does not come instantaneously, thus removing the possibility of making an immediate alternative selection. However, Quelle might have put up a list of all items out of stock on the central videotex computer as well and "hidden teleprogram" [6-8] would have instantaneously informed the user, allowing him an alternate selection.

The advantages of the method - however - are, first, that the user does not need to wait long (especially if the system is overloaded) for the gateway and the network when communicating with the third party computer and, second, the third party computer does not have to bother about its possible overload by simultaneous users requests, since the processing of the requests can be done serially, practically in "batch" regime.

In another typical application - telebanking basically the following services are performed:

(i) banking transactions

(ii) information about bank services and status of own account

(iii) currency exchange calculations

(iv) mortgage and credit calculations.

These application categories are realized, for example, in the present videotex trial in the FRG, with the help of a gateway to a third party computer. The last two categories could alternatively be easily done by putting up more information frames and tables on the system. This would certainly be a feasible solution but not a nice and user friendly one. A much better alternative is to use an intelligent videotex decoder, to download the currency exchange calculation program needed. This in turn would automatically look up during program execution the needed currency exchange rates from the videotex currency exchange information page. Another major advantage of this 
technique is that it not only requires no interactive gateway in the system, but also is not disturbed by third party system overloads. In the FRG, for example, shortly after a major bank's computer was linked to the videotex trial, the currency exchange calculation service had to be stopped from time to time, since simultaneous user requests for this service (most of them certainly from users "playing" with this new gadget) overburdened the bank computer to the extent that no other services - such as banking transactions - could be performed.

Banking transactions - either from the consumer to the bank or vice versa - could be done through the videotex message service equally well. As with the previous teleshopping application, both transaction and confirmation would be "sequential" and not instantaneous, although this would not be disturbing to the user.

Information about general bank services could be put - as is usually the case - onto the "standard" videotex database.

Information about the status of the customer's own account could be provided in different ways, which also do not require an interactive videotex gateway.

First, the bank could send "messages" about the status of the customers' bank account at predefined time intervals through the videotex message service. Second, the bank could set up for each customer a "Closed User Group" separately that would allow only him to access it. Third, all customers' account information could be put on "standard" videotex pages, openly accessible, if it was encoded, for example, according to a public key system. In this manner the necessary decryption software could be downloaded in an intelligent videotex decoder such as MUPID [8], and by means of the secret decoding key decrypted by the customer.

All in all, including the above cases, no truly interactive gateway to a third party computer is really needed in a videotex system.

What is needed is either an intelligent videotex decoder to collect, execute, and reply to incoming requests in the form of videotex messages in a stand-alone way, or a "not real time" gateway with buffering capabilities, which acts as a mailbox between the videotex system and the third party computer. Luckily - as described in ref. 8 this function can be easily solved by the same intelligent videotex decoder. In this manner, from the videotex network point of view, the gateway looks just as any ordinary videotex user or information provider terminal, but it acts for the third party computer as a kind of front-end towards the videotex system.

Supposing an information provider and owner of a third party computer wants to process his incoming videotex requests three times a day, such an intelligent videotex decoder, with a built in and preprogrammed timer would automatically establish connection to the videotex system as an ordinary user, it would collect from its videotex mailbox all piled up messages, store them locally for further processing by the third party computer in the next processing cycle, and distribute the reply messages into the mailboxes of users whose requests have been processed by the third party computer in the previous cycle.

\subsection{Updating of Information}

Last but not least some aspects of updating information in videotex networks should be mentioned. Updating information of the videotex master database can be done either in interactive or batch mode; it can also be done either in an online or an offline regime. We describe here this second classification:

\subsubsection{Off-Line Update}

The off-line update of information is a kind of so-called "bulk-update" of larger information quantities at the user's site.

1) In this manner new information updates are generated on the user's own computer and put on magnetic tape in a predefined format. The tape is then sent to the central videotex database computer and is fed into the system by the videotex operator in a batch regime for update.

2) The second way of updating information in an "offline" regime is by means of an editing terminal or by using an intelligent videotex decoder [8]. In this form the videotex network provides for direct connection between the information provider's terminal and the videotex master database center. In some of the present systems this update is relatively slow; in recent videotex networking plans, such as for Austria, 2400 baud links are recommended. Whereby new information updates are generated on the 
user's own terminal in an "offline" regime and the edited pages are transmitted in a "bulk mode" over telephone lines to the videotex center.

\subsubsection{On-Line Update}

In videotex systems - such as in the West German IBM videotex concept - there is also an option to use the DATEX-P packet switching network between the external information provider's computer and the videotex master database (Figure 2). In this way the inconvenient and slow physical transport of the tape can be avoided and the master database can be bulk-updated without manual interaction by the videotex service operator.

\section{Linkage of Inhouse and Public Videotex Sys- tems}

In addition to (trials involving) public videotex systems, many versions of inhouse videotex systems are available and in use worldwide $[1,11]$. In a way this is somewhat surprising since such systems are really nothing more than very simpleminded time sharing terminal systems with rather clumsy terminals. In particular, a Prestel-type terminal is definitely less convenient to use than an average computer terminal. The reason for this is more conceptual than economical.

The (modest) success of such terminals and inhouse videotex systems can be traced, it appears, to the following facts:

(i) The color component seems to be a big attraction to the naive user;

(ii) The simple numeric-key pad is not seen as a severe drawback at the time of acquisition but is (and we believe wrongly) seen as a guarantee for simple use. After all, if there are only 12 keys for control, surely the system must be easy to use, goes the argument. As we have claimed elsewhere [2,3] such arguments are fallacious, numeric keypads having (maybe) a fleeting positive effect psychologically, but nothing but drawbacks, otherwise.

(iii) Videotex terminals are comparable in price with ordinary black and white computer terminals; many of them are also usable as TV receivers. (Indeed it has been speculated that videotex terminals are partially a success due to the fact that they allow the tax-deduct- ible acquisition of color TV sets.)

(iv) Inhouse videotex systems (hardware and software) are offered for attractive package-prices, and the low pricing is supported by the fact that videotex software is much less sophisticated, and hence cheaper than software encountered in other information systems.

Overall there are some reasonable but not compelling reasons for setting up an inhouse Videotex system. It is our contention in this section, and one of the main claims of this paper, that inhouse videotex systems gain much in attractivity by conceiving them as "front-ends" of a public videotex system. Indeed we belive much of the potential success of public videotex systems may hinge on the successful marriage with inhouse systems.

In the following section we first present our concept of an inhouse videotex system with a "transparent link" to public videotex. We then explain the sizable benefits of such a combination and point out how the "dreaded" copying of information can be turned into a useful and desirable feature.

\subsection{Inhouse Videotex Systems with a Transparent link to Public Videotex}

In the following we consider what we will call an inhouse intelligent ("IIVTX", for short) videotex system:

(i) Its terminals are intelligent terminals in the sense of [4-6] such as the terminal MUPID $[7,8]$, i.e., the terminals have an alphanumeric keyboard, offer various aids for searching, allow for the local storage of information, the creation and execution of, for example, basic programs and thus the use of telesoftware $[9,10]$.

(ii) The frame access structure in the IIVTX system is identical to the one in the public videotex system. For example, if the public Videotex system is Prestel like, then the access structure in the IIVTX is also a tree structure with numeric page labels.

(iii) The page labels in the IIVTX can be recognized as belonging to the inhouse system, rather than being labels of frames in the public system (e.g. because completely different sets of labels are used).

(iv) The IIVTX is connected via a permanent data 
link, or a data link dialed up when needed, to the public videotex system. Any frame request or the like not satisfiable in the IIVTX is routed to the public videotex system. The IIVTX has, thus, a "transparent link" to the public videotex system: the IIVTX handles all requests it is able to, and passes all others on to the public system. The user should not really be aware of this: his requests are promptly answered, he should not care how.

The advantage of using an IIVTX over using a stand-alone inhouse videotex system are obvious: the transaction capability of a large videotex network becomes available [3] and large amounts of public information. The advantages of using and IIVTX instead of just using a public videotex system are at least fourfold:

(1) Cost

(2) Privacy/data security

(3) Speed

(4) Decentralization.

We will discuss now each of the above points at some length.

\subsubsection{Cost}

When using public videotex services there are essentially five cost components: (i) the terminal, (ii) the modem, (iii) telephone connect charges, (iv) page charges, and (v) videotex subscription charge.

The five categories mentioned vary from country to country and depend on a number of factors. For instance, neither the FRG nor Austria have any subscription charge, nor do they levy any connection charges beyond telephone charges. In contrast, in the UK both connect and substantial subscription charges (US\$ 60 per month) are collected. On the other hand, modems can be purchased in the UK, but have to be rented from the PTT in the FRG and Austria (for rather different monthly charges: US\$ 3 in the FRG, US $\$ 15$ in Austria). Similar discrepancies can be noticed in the other categories. All these discrepancies and different pricing policies are due to the fact that videotex systems of today are generally subsidized by governments. In addition, equipment prices are supposed to reduce significantly in the near future, and the question of how to split the cost of operating a videotex system between the systems operator (who often, as PTT, supposedly will obtain additional revenue by the increased usage of its telephone network), the in- formation providers (who could pass on costs to users, if they wished, via page charges), and the user, is still open.

To be able to present arguments based on concrete figures we will focus on the situation in Austria. The choice of Austria is not just motivated by the authors' affiliation but by three facts:

(a) Austria had decided to use intelligent videotex terminals, a decision likely to be taken sooner or later in most countries and likely to influence the development of videotex significantly $[6,7,8]$;

(b) Neither terminal nor modem prices are significantly subsidized but reflect commercial realities;

(c) The fact that videotex is accessible all over Austria for only local phone charges (US\$ 1.8 per hour) assures a strong communicative aspect of videotex, as we believe it indeed should.

In Austria, the five cost categories mentioned above are as follows: an intelligent terminal (using existing TV sets) can be rented from the PTT including a modem for about US\$ 17 per month. Telephone connect charges for videotex are US\$ 1.8 per hour, country-wide. There are no connect and no subscription charges and very few pages with page charges. For an IIVTX, intelligent terminals (MUPID, see [6-8]) can be obtained (including color TV sets) for about US\$ 1000 per unit.

Let us now assume a scenario in which videotex is used in a company for many activities including country-wide messaging, teleconferencing, inhouse communication, project documentation, etc. In such a case a daily usage of two hours per terminal is not unrealistic. By using an IIVTX with a transparent link to the public videotex system, only some $20 \%$ of this will be using telephone links, the rest will be inhouse traffic.

Under the above assumptions a rough costcomparison obtained for Austria is shown in Table 1. This Table shows that an IIVTX with a transparent link to a public videotex system compares well from a cost point of view with the situation when only public videotex system is used; the cost of IIVTX is smaller than the costs for telephone line usage if only public videotex is used.

If this is added to other favorable aspects to be discussed below it becomes clear than an IIVTX with a transparent link is a highly attractive alter- 
Table 1

\begin{tabular}{|c|c|c|}
\hline & $\begin{array}{l}\text { Public VTX } \\
\text { system }\end{array}$ & $\begin{array}{l}\text { IIVTX with transparent } \\
\text { link to publication VTX }\end{array}$ \\
\hline Terminal & & 1) \\
\hline (without TV) & 8 & 12 \\
\hline \multirow[t]{2}{*}{ Modem } & & 2) \\
\hline & 12 & - \\
\hline TV & 8 & 8 \\
\hline Telephone & & 3) \\
\hline line & 72 & 15 \\
\hline \multirow[t]{2}{*}{ IIVTX } & 2) & 4) \\
\hline & - & 45 \\
\hline $\begin{array}{l}\text { Total costs } \\
\text { (per month }\end{array}$ & & \\
\hline in US\$) & 100 & 80 \\
\hline
\end{tabular}

1) The terminal is more expensive in this case, since the centralized distribution system of the PTT cannot be used.

2) This equipment is not necessary in this case.

3) $15=20 \%$ of 72

4) Based on the assumption of some 50 useres of a US\$ 100000 videotex system.

native. Some PTTs, however, are quite reluctant to permit IIVTX's with transparent links, fearful of reduced usage of their own videotex system. We would like to state our belief that such fears are ill-founded: videotex for inhouse communication and other purely inhouse purposes will not be a success without the availability of IIVTX's with transparent links. Hence, supporting the idea of IIVTX's with transparent link will help the rapid penetration of videotex on the whole and in this fashion will benefit the PTT as the operator of the telephone system. We turn now to the other aspects of IIVTX's with transparent links.

\subsubsection{Privacy / Data Security}

Videotex will be most successful it if can be used for a very wide range of applications. No matter what safeguards are provided by public videotex operators (from the system itself or through cryptographic measures) institutions will be reluctant to store sensitive information (i.e., material of potential help for a competitor) in a public videotex system. They will not (and probably are ill-adviced if they did) believe any assurance of guaranteed privacy and secrecy. Thus, sensitive information is kept, and will continue to be kept - for vulnerability reasons - in inhouse information systems. If such systems (e.g., IIVTX's) have no transparent link to public videotex, the universality of the videotex system - as a single unit - with more or less automatic routing to whatever service is desired is endangered and the penetration of videotex in general could be slowed considerably.

\subsubsection{Speed}

For many situations the speed of public videotex is irritatingly slow: the dial-up procedure takes some 60 seconds (if one is lucky enough to get through to the videotex computer the first time around), the loggin-in (designed to handle, after all hundreds of thousands of users at some stage) is complicated. Then, after logging in, ending on page 0 of the public system might be less convenient than to be routed directly to some company specific index. In addition, the transmission rates via the telephone lines that are currently in use are painfully slow (see [6]), in particular when telesoftware is loaded or worse, generated [6,9], necessitating waiting times, slow build-up of graphical frames, etc.

All of these inconveniencies disappear when an IIVTX with a transparent link is used: logging in on an IIVTX might be done with a short code, no waiting for the dialing up of a phone number is necessary in most instances *, the user may be guided to a company specific index directly, and data transmission between the user terminal and the IIVTX may be carried out at high baud rates on local lines.

\subsubsection{Decentralization}

The idea of an IIVTX with a transparent link to public videotex is also attractive from an overall system point of view: a videotex user has an intelligent videotex terminal with some decentralized processing and storage. Local applications like inhouse communication, printing a page edited on the videotex terminal, looking up some company statutes, etc. are all done in the IIVTX. Cross-country communications, searching vast public databanks, etc. are done via the public

\footnotetext{
* Even if the IIVTX has no permanent link to public videotex, but just a dial-up phone link, and even if communication with the public videotex is desired, the user sometimes does not have to wait for the dialing: e.g., when he needs to send a message, the IIVTX may transfer that message to the public videotex after the user has already logged-out of the IIVTX.
} 
system. A nicely layered system, each component performing those tasks it is best suited for is thus provided. Some fascinating combinations seem feasible, extending the ideas of chapter 2.2. Just as an example, assume that a user with a videotex terminal A wants to run a program $\mathrm{P}$ written in a language $\mathrm{X}$ not available on $\mathrm{A}$ or on the IIVTX computer C. P might be sent - via the public videotex system - to some third party computer where a compiler translated $\mathrm{P}$ into a machine-code for $C(!)$. Now the translated program can be executed on the IIVTX computer C, and the results passed on to $\mathrm{A}$.

Sophisticated cross-compilers available on third party computers may help much, by using videotex and IIVTX's with transparent links, to overcome frequently encountered compatibility problems.

\subsection{Local Storage and Updating of Large Volumes of Data}

IIVTX's are supposedly used mainly to store local information, for inhouse communication, for "concentrating" videotex users to obviate the need for a separate modem and phone line for each user. But IIVTX's will supposedly route most other requests to the public videotex system.

However, it is clear that IIVTX could also be used to retrieve and store the most often used frames from the public system just once and hold them for arbitrary frequent inhouse retrieval in the IIVTX, each page thus only being charged once!

This possibility is certainly "dreaded" by all information providers. We feel that it might influence pricing policy for pages in public videotex but that it is much less of a problem than one would think on first glance if:

(a) the transport of data via videotex (as in case of Austrian local phone-connect charges countrywide) is somewhat less expensive than via other data channels and if:

(b) page charges either do not exceed some US $\$ 0.01$ or else must be especially "protected" (see below).

We would like to elaborate our claims in some detail. Suppose a frame available in public videotex has a charge of US\$ $0.01 *$ and a company -

* Note that a typical newspaper whose videotex edition would have to have 100 frames to match some ordinary newspaper pages would already amount to US\$ 1 . knowing that this frame will be of interest company wide - decides to downland it into an IIVTX. Clearly, all people directly hooked up to that IIVTX will now be able to retrieve that page without any further charges. Note however, that this number will be reasonably limited. Only by copying the frame via some data link into other IIVTX's of the company (e.g. using the public videotex system) or by retrieving it via some data link (e.g. packet-switching) from the first IIVTX, would access become widespread. However, the copying of one frame via public videotex from one IIVTX to another requires about 15 seconds of a phone line (as minimum) amounting to approximately US\$ $0.01^{* *}$. Thus, it is more convenient and not more expensive if all other IIVTX's retrieve the same frame directly from the public videotex system. The access of a single huge IIVTX owned by a company via other data networks does not bring a net gain by a similar calculation.

Hence, problems only arise with frames with high charges. It may well be that frames with much higher charges will turn out to be quite rare. Even for telesoftware US\$ 0.01 may be quite sufficient [9]: a telesoftware-game of moderate length (say 10 frames) would already net US\$ 0.1 and, if reasonably popular, will make a considerable amount of money even if the number of videotex users is still moderate $* * *$.

Still, even the protection of frames with high page charges is possible (even if copyright laws cannot be applied) by either putting them into CUGs or by combining them with a piece of telesoftware (assuming an intelligent videotex decoder such as MUPID [6,7,8] is available). Typically, the information at issue will be encrypted (scrambled) and will only be decrypted by the telesoftware when the actual time the program is retrieved (which is stored into the program at the time of retrieval in a spot of the information unknown to the user) matches (up to a few seconds) with the current system's time *.

** All calculations are based on Austrian rates as explained earlier.

*** After all, 20000 users - as in the UK - playing such a game just once a month on the average yields already US\$ 2000 per month.

* As simple as such measures are, they require much work even for knowledgeable users to overcome them. A number of such measures are taken to protect the telesoftware in Austria's videotex system [6]. 
The above considerations show that information providers of public videotex systems need not be concerned about losing most of their revenue if pages are copied into IIVTX's: if page charges are below US $\$ 0.01$ copying will always be only for a comparatively small group of users, and if page charge are high, protective measures are possible.

We believe that information from public videotex will indeed be copied into IIVTX's to some extent, mainly for reasons of speed rather than for reasons of cost. There are two likely approaches that we feel might well be used together.

The first approach is to keep a pool of frames (potentially as many as still fit into space not otherwise used on the IIVTX's disc or other external storage device) with a "frequency count": every time a frame is requested from public videotex not in that pool, that frame replaces the frame with lowest frequency-count ${ }^{* *}$ and is given some initial frequency count; every time a frame of the pool is requested its frequency is increased; the frequency-count of all frames is decreased at certain intervals (e.g., once a day) by a certain amount (to ensure that frames that have been requested often at some stage but have not obtained much attention later on will finally be removed again); finally, if space is required on the IIVTX's disc the pool of frames is reduced by deleting frames with the lowest frequency counts. Observe that special measures have to be taken that frames whose contents have changed in the public videotex system are not available in their obsolete form in the IIVTX, otherwise the whole concept can fail.

We find it conceivable that information providers will cater for the needs of IIVTX's by actually providing special frames (maybe with page charges) listing those frames that have changed, or by even sending messages informing about changes to all those IIVTX's who have subscribed (for some fee) to that service. Thus, we do not see the IIVTX's as something endangering public videotex or the revenues of information providers but rather as large potential customers.

This brings us to the second approach of storing parts of the public videotex frames in a IIVTX. For special user groups it may be of interest to copy the full information program of some information provider into an IIVTX (tables of ex-

** Observe the analogy to the videotex network concept of IBM mentioned in chapter 1 . change rates; train schedules; offers for tenders, etc.). Again this will and should not be in conflict with the information providers' interests. By charging a small amount for each frame, once-only retrieval of all pages might well create more revenue than the frequent retrieval of only some of the pages. Despite this potential increase in cost the user of an IIVTX might well prefer such an approach to avoid the dial-up and other inconveniencies when looking up a single item of of ten necessary information. By offering an update service as described above the local storage of some information will still be more attractive.

\subsection{Flexible, Convenient, and Cheap Realizations of "Countrywide Private Network" Through Public Videotex Systems}

Often when there is a demand for an inhouse videotex system a star-shaped inhouse videotex system does not prove to be sufficient in the long run. Imagine a nationwide bank, a transport company or a factory deciding to run an inhouse information and transaction system. If one central videotex center is used, then the telecommunication component of such a system has to be more developed, requiring expensive telecommunication channels and equipment. In addition most of the information transmission is in fact unnecessary if, for example, local information is stored and retrieved or local transactions are performed. For such cases ideally interconnected local inhouse intelligent videotex system (IIVTX) should be applied and linked together in order to reach nationwide coverage. Ideally this could be done through the public videotex system. In such a manner the bank, company, organization, etc. could become a CUG of the national videotex system, but each or some members of the CUGs would be IIVTX systems. Here the inhouse videotex systems would take advantage of the sophisticated computer networking aspect of a national system.

\section{Summary}

Summarizing, we feel strongly that "integrating" inhouse videotex systems as IIVTX's into public videotex system is an important task to be undertaken. Such integration will not be detrimental to public videotex systems (as is sometimes 
feared unjustifiably) but will rather stimulate videotex penetration as a whole. We are convinced that nothing would hurt and possibly endanger videotex more than the emergence of rival and non-cooperating videotex systems on various levels. Only the integration of the various types of videotex will provide the user the convenient access he can have and he should have. Only if such convenient access is available will videotex be a success. And then and only then will the videotex operators and information providers have a profitable undertaking.

\section{References}

[1] Viewdata/Videotex Report, March 1982. 3, 3 LINK, New York.

[2] H.A. Maurer, W. Rauch, I. Sebestyen, 1981. On Alphabetic Searching in Videotex Systems. Electronic Publishing Review, Vol. 1, 217-223, Learned Information, Oxford.

[3] H.A. Maurer, W. Rauch, I. Sebestyen, 1981. Videotex Message Service Systems. Electronic Publishing Review, Vol. 1, 267-296, Learned Information, Oxford.
[4] H.A. Maurer, 1981. Bildschirmtext ähnliche Systeme Study prepared for the Austrian Federal Ministry for Science and Research. Report B11, IIG, Graz. Austria

[5] H.A. Maurer, I. Sebestyen, 1982. One-way Versus Two-way Videotex. WP-82-30, IIASA, Laxenburg, Austria.

[6] H.A. Maurer, R. Posch, 1982. How to Further Improve Interactive Videotex. Research Report 88, IIG, Graz.

[7] H.A. Maurer, 1982, Will MUPID Revolutionize Austria's Videotex?, Videotex '82, Proceedings of Conference, 187-198, June 28-30, New York.

[8] H.A. Maurer, R. Posch, 1982. MUPID - An Austrian Contribution to Videotex, Report F87, IIG Graz, Austria.

[9] H.A. Maurer, I. Sebestyen, 1982. On Some Non-Standard Applications of Videotex, Videotex '82, Proceedings of Conference, 199-210, June 28-30, New York 199-210.

[10] H.A. Maurer, I. Sebestyen, 1981. Unorthodox Videotex Applications - Teleplaying, Telegambling, Telesoftware and Telecomputing. WP-81-161. IIASA, Laxenburg, Austria.

[11] Alan J. Mayne, 1982. The Videotex Revolution, the October Press, Fareham, UK.

[12] Anonymous, 1982. Das IBM Konzept für die Bildschirmtext-Zentralen in der Bundesrepublik, Bildschirmtext Aktuell. Vol. 3, No. 45, Neue Pressegesellschaft mbH, Ulm, FRG.

[13] D. Becker, R. Ertelt, 1980. Ein Netzkonzept für den Bildschirmtext - Dienst: "Text- und Bildschirmkommunikation". VDE Verlag GmbH, Gerling, FRG. 

